\title{
A comparison between vertical motions measured by ADCP and inferred from temperature data
}

\author{
H. van Haren \\ Royal Netherlands Institute for Sea Research (NIOZ), P.O. Box 59, 1790 AB Den Burg, The Netherlands
}

Received: 6 March 2008 - Published in Ocean Sci. Discuss.: 14 April 2008

Revised: 12 June 2008 - Accepted: 1 August 2008 - Published: 3 September 2008

\begin{abstract}
Combined vertical current (w) and thermistor string data demonstrate that high-, near-buoyancy frequency internal "wave" trains along a pycnocline in a flatbottom shelf sea consist for 2 periods of a dominant mode- 1 non-linear part, while thereafter mainly of linear [mode-2, quadrupled frequency] waves, to first order. In a simple [linear] heat budget the use of unfiltered temperature gradient or its time mean changes results by only $10 \%$. The observations also demonstrate that temperature is not always adequate to estimate vertical motions using the linear 1-D heat equation. In shallow seas, tidal-w estimated from temperature data can be an order of magnitude weaker than directly observed w, and thus do not represent free internal waves. In the ocean, not too far from the main internal wave topography source, tidal motions represent linear waves and are well described by temperature-inferred $\mathrm{w}$. There however, temperatureinferred $w$ and directly observed w differ strongly near the buoyancy frequency, at which $w$ is dominated by non-linear waves, and near [sub]inertial frequencies, at which $w$ is dominated by eddies and gyroscopic waves.
\end{abstract}

\section{Introduction}

The recognition of the importance of internal wave breaking for ocean mixing, with relevance for redistribution of suspended matter, justifies some detailed study of motions near the buoyancy frequency N. At this high-frequency limit of the internal wave band, motions are considered nearly vertical, so that they can be studied by monitoring vertical currents (w), see, e.g., Inall et al. (2000). This current component is not often measured in the ocean or shelf seas, because

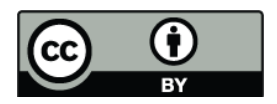

Correspondence to: H. van Haren (hansvh@nioz.nl) the aspect ratio is usually $\mathrm{O}\left(10^{-2}-10^{-3}\right)$ and when it is $\mathrm{O}(1)$ like near $\mathrm{N}$ spatial scales tend to be small.

Thus, a common method for monitoring $\mathrm{w}$ is using more easily measurable temperature variations under the assumption of a reduced heat equation that is dominated by only two terms (e.g., Krauss, 1966),

$\frac{\partial \mathrm{T}}{\partial \mathrm{t}}=-\mathrm{w} \frac{\partial \overline{\mathrm{T}}}{\partial \mathrm{z}}$,

where the overbar denotes a time mean. Other advection, non-linear and diffusive terms are considered small and temperature must be a conservative quantity. As in a stably stratified sea, in regions where salinity contributions are small, the vertical derivative of slowly varying temperature is positive, $\mathrm{W}$ and $\mathrm{T}$ describing free wave motions will always be $\pi / 2$ out of phase following Eq. (1), with w leading T. The use of Eq. (1) to estimate w requires vertical profiles of temperature besides sufficient temporal resolution.

Alternatively, one could estimate $\mathrm{w}$ from vertically densely spaced temperature sensor data after converting the series $\mathrm{T}(\mathrm{z}, \mathrm{t})$ to isotherm displacements $\eta(\mathrm{T}, \mathrm{t})$. However, as mentioned by Pinkel (1981), over any prolonged period of time isotherms will wander in- and out of a finite window of observations, which makes the computation of $\eta$ impossible. Likewise, closed contoured overturning areas render ambiguous results, so that the $\eta$ will be biased towards coherent motions.

Although the use of Eq. (1) preferentially requires a full sequence of thermistor string data, which is not always available, the mean vertical temperature gradient may be estimated from a single CTD-profile using a suitable vertical length-scale for smoothing. This has recently been used for ocean data obtained not too far from the continental slope in a comparison between w inferred from Eq. (1) and w directly measured by acoustic Doppler current profiler (ADCP) (van Aken et al., 2007 and Fig. 1). In general, the agreement between the two data sets is reasonably good. Some statistically

Published by Copernicus Publications on behalf of the European Geosciences Union. 


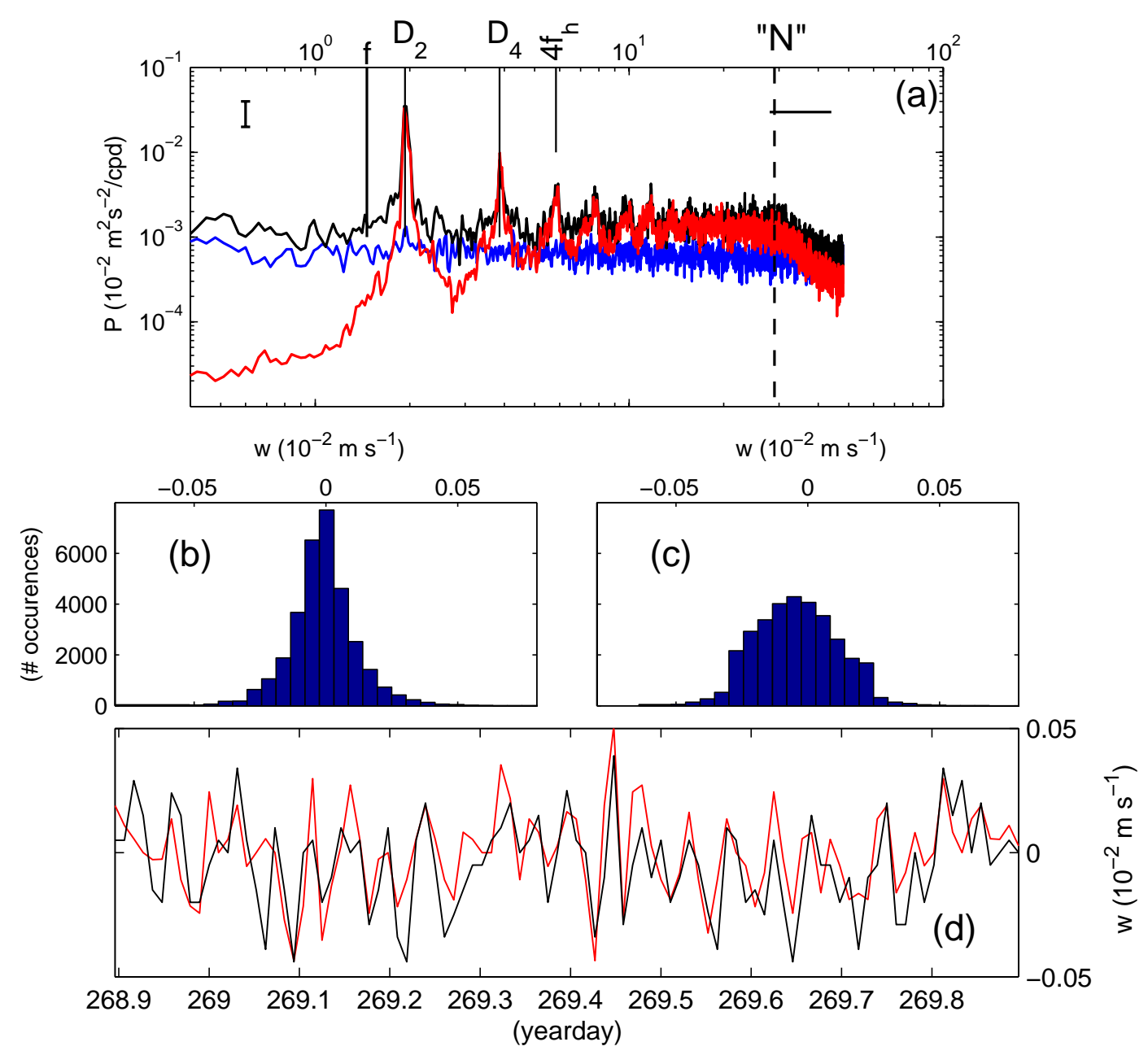

Fig. 1. (a) Frequency spectra (in cycles per day) of w-data in the Bay of Biscay measured at $46^{\circ} 43^{\prime} \mathrm{N}, 5^{\circ} 24^{\prime} \mathrm{W}$ (water depth $\mathrm{H}=1600 \mathrm{~m}$ ), using $75 \mathrm{kHz}$ ADCP at $1040 \mathrm{~m}$ (black) and compared with instrumental, measurement noise (blue) and w inferred from ADCP's temperature data at $1100 \mathrm{~m}$ using Eq. (1) with CTD-data to estimate mean vertical gradient (red), partially after van Aken et al. (2007). The CTDestimated buoyancy frequency $(\mathrm{N})$ range is indicated with a horizontal line; the horizontal component of the Coriolis force is indicated by " $f_{h}$ " and discussed in Sect. 3.1. (b) Histogram of red, temperature inferred w-data in (a). (c) Histogram of black, ADCP-observed w-data in (a). (d) 1-day detail of time series of w-data in (a-c) showing near-N oscillations.

significant discrepancies are found near $\mathrm{N}$, in the continuum near the low-frequency part of the internal wave band and near the inertial frequency $f$. The best agreement is found for the tidal harmonic peaks $\mathrm{M}_{2}$ and $\mathrm{S}_{2}$ in the semidiurnal tidal band " $\mathrm{D}_{2}$ " and for the continuum near frequencies $\sigma=15$ $20 \mathrm{cpd}$, cycles per day, or just below N (Fig. 1). Histograms of differently estimated w show misfits (Fig. 1b, c), with a non-zero bias for ADCP-data. In the time domain, regularly small-scale data show rather good comparison down to the fastest near-N motions (Fig. 1d). The larger discrepancies, that is weaker values for temperature-inferred w, at $\sigma<\mathrm{f}$ and $\sigma>\mathrm{N}$ were attributed by van Aken et al. (2007) to ADCPnoise. It is noted here that this noise is only partially instrumental white noise for the latter frequencies. It is even partially non-white "noise" due to current inhomogeneity for the former, as inferred using the redundant fourth beam providing the "error velocity" (Fig. 1a). This is somewhat curious as one would not expect dominant motions at scales smaller than the ADCP's beam spread at sub-inertial frequencies.

Here, only data from four-beam ADCP will be used. Such instrument can measure w reasonably well, despite the generally low oceanic aspect ratio, because: i) its beam angles are slanted at an angle $\theta=20^{\circ}$ to the vertical thereby favouring vertical over horizontal currents by a factor of 3 , ii) its accurate tilt sensors and precise beam alignment allow corrections for $<1^{\circ}$-variations, iii) errors also due to current inhomogeneities across the horizontal beam spread are retained by considering the data from the redundant fourth beam. 
Table 1. RDI-broadband uplooking-ADCP mooring details. INP is in the central North Sea, PROCS in the Faeroe-Shetland Channel.

\begin{tabular}{lll}
\hline & INP summer & PROCS spring \\
\hline Data start & $13 / 07 / 1994$ & $19 / 04 / 1999$ \\
Data end & $21 / 07 / 1994$ & $01 / 05 / 1999$ \\
Latitude & $54^{\circ} 25^{\prime} \mathrm{N}$ & $60^{\circ} 49^{\prime} \mathrm{N}$ \\
Longitude & $004^{\circ} 02^{\prime} \mathrm{E}$ & $003^{\circ} 00^{\prime} \mathrm{W}$ \\
Water depth $(\mathrm{m})$ & 45 & 494 \\
Vertical slant angle $(\theta)$ & $20^{\circ}$ & $20^{\circ}$ \\
Transmit frequency & $600 \mathrm{kHz}$ & $600 \mathrm{kHz}$ \\
Transmission length & $1.9 \mathrm{~m}$ & $1.2 \mathrm{~m}$ \\
Instrument depth & $0.3 \mathrm{~m} \mathrm{a.b.} \mathrm{bottom}$ & $1.7 \mathrm{~m} \mathrm{a.b.}$ \\
First bin & $3.1 \mathrm{~m} \mathrm{a.b.}$ & $3.8 \mathrm{~m} \mathrm{a.b.}$ \\
\# bins $\times$ bin size & $90 \times 0.5 \mathrm{~m}$ & $60 \times 0.5 \mathrm{~m}$ \\
Ensemble period & $150 \mathrm{~s}$ & $30 \mathrm{~s}$ \\
Std u, v & $0.006 \mathrm{~m} \mathrm{~s}^{-1} / \mathrm{ens}$ & $0.012 \mathrm{~m} \mathrm{~s}^{-1} / \mathrm{ens}$ \\
Std w, e & $0.002 \mathrm{~m} \mathrm{~s}^{-1} / \mathrm{ens}$ & $0.004 \mathrm{~m} \mathrm{~s}^{-1} / \mathrm{ens}$ \\
\hline
\end{tabular}

As:

$\mathrm{w}_{\mathrm{o}}=\mathrm{w}_{\mathrm{r}}+\left(\left.\Delta\right|_{\mathrm{x}} \mathrm{u}_{\mathrm{r}}+\left.\Delta\right|_{\mathrm{y}} \mathrm{v}_{\mathrm{r}}\right) \tan (\theta) / 4$,

where subscript ${ }_{o}$ denotes "observed" and $r$ "real" and where $\left.\Delta\right|_{x}$ indicates finite difference across the beam spread in $\mathrm{x}$ direction, likewise for the $y$-direction, the "error velocity" reads:

$\mathrm{e}_{\mathrm{o}}=\left(\left.\Delta\right|_{\mathrm{x}} \mathrm{w}_{\mathrm{r}}-\left.\Delta\right|_{\mathrm{y}} \mathrm{w}_{\mathrm{r}}\right) / 4-\left(\left.\Delta\right|_{\mathrm{x}} \mathrm{u}_{\mathrm{r}}-\left.\Delta\right|_{\mathrm{y}} \mathrm{v}_{\mathrm{r}}\right) \tan (\theta) / 4$

Henceforth, dropping all subscripts, observed e will be used as error benchmark for observed w.

In this note the focus is on details of the above discrepancies with the aim to learn more about the importance of non-linear internal waves and tidal (frontal) advection and to verify whether the above discrepancies are due to the use of mean temperature gradient from CTD-profiles or other neglected terms in Eq. (1), as noted by Krauss (1966). For this purpose, simultaneous ADCP and thermistor string data from a shelf sea interior and a continental slope will be scrutinized. Hereby, the particular disadvantage of ADCP, the averaging of all three Cartesian current components across horizontal distances $\mathrm{O}(10-100 \mathrm{~m})$, because its beams are slanted at $\theta=20^{\circ}$ to the vertical, is considered as well. This limits the study to phenomena having horizontal scales $>100 \mathrm{~m}$.

\section{Data}

Vertical motions are investigated using four-beam ADCPand thermistor string data from a site in the central North Sea in summer 1994 (project INP) and from a site in the FaeroeShetland Channel "FSC" in spring 1999 (PROCS). At both sites, the ADCP is mounted in a frame that is rigidly moored at the bottom showing no tilt variations with time.

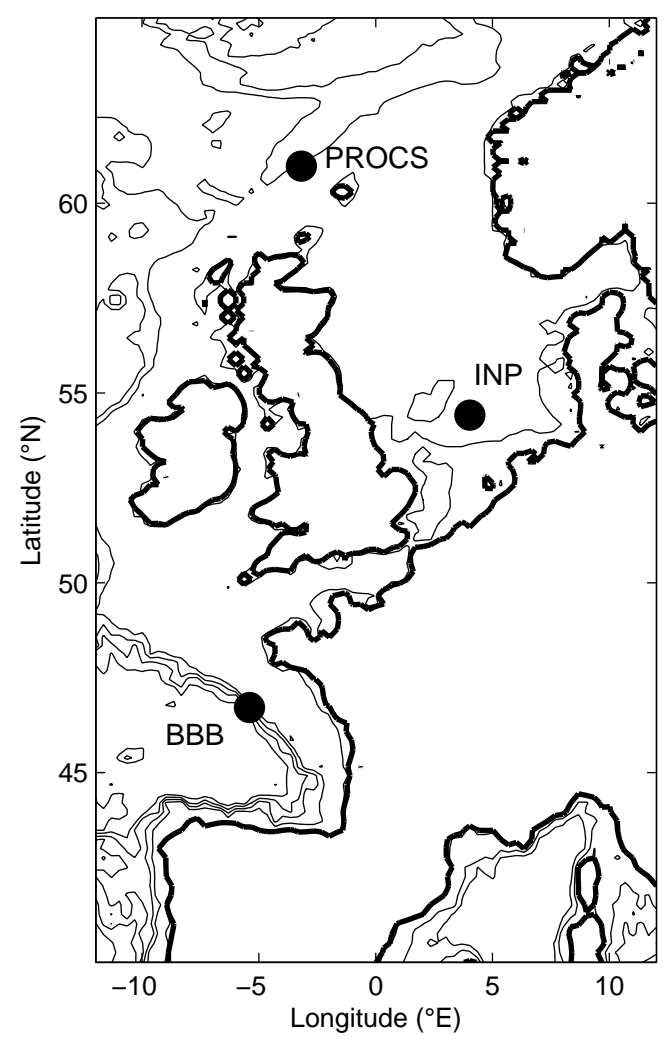

Fig. 2. Mooring locations (•) in North Sea (INP), Faeroe-Shetland Channel (PROCS) and Bay of Biscay (BBB).

Fig. 2 shows mooring locations and Table 1 lists mooring details. In 1994, Aanderaa thermistor strings are used. It is noted that although the manufacturer of these temperature sensors claims an absolute accuracy of "only" $0.1^{\circ} \mathrm{C}$ (Table 2), the relative accuracy of Aanderaa's resistors is much better, even below the resolution of digitization. This explains the ability to measure confidently the weak stratification at the top of the bottom "mixing" boundary layer (Sect. 3). In 1999, a NIOZ-designed high-resolution thermistor string was used.

The flat-bottom INP mooring site in the central North Sea ( $\mathrm{H}=45 \mathrm{~m}$ water depth) is well within the region of seasonal, predominantly thermal, stratification, and generally away from large frontal zones. The 8 days observational period is characterized by strong stratification mainly supporting large near-inertial motions and shear, strong insolation except for the first day and weak winds. Despite the [tidal] shearinduced turbulent friction, the near-bottom layer is not homogeneous but persistently shows a [minimum] stratification for which the buoyancy frequency $\mathrm{N} \approx 5 \cdot 10^{-4} \mathrm{~s}-1$, or $\sim 4 \mathrm{f}$. In this layer, larger stratification resulting in larger $\mathrm{N}$ are observed during particular phases of the tidal current with typical buoyancy periods $\mathrm{T}_{N}$ ranging between 1500 and $2500 \mathrm{~s}$. Similar values are found above the pycnocline. In the pycnocline itself stronger stratification results in $300<\mathrm{T}_{N}<500 \mathrm{~s}$. 

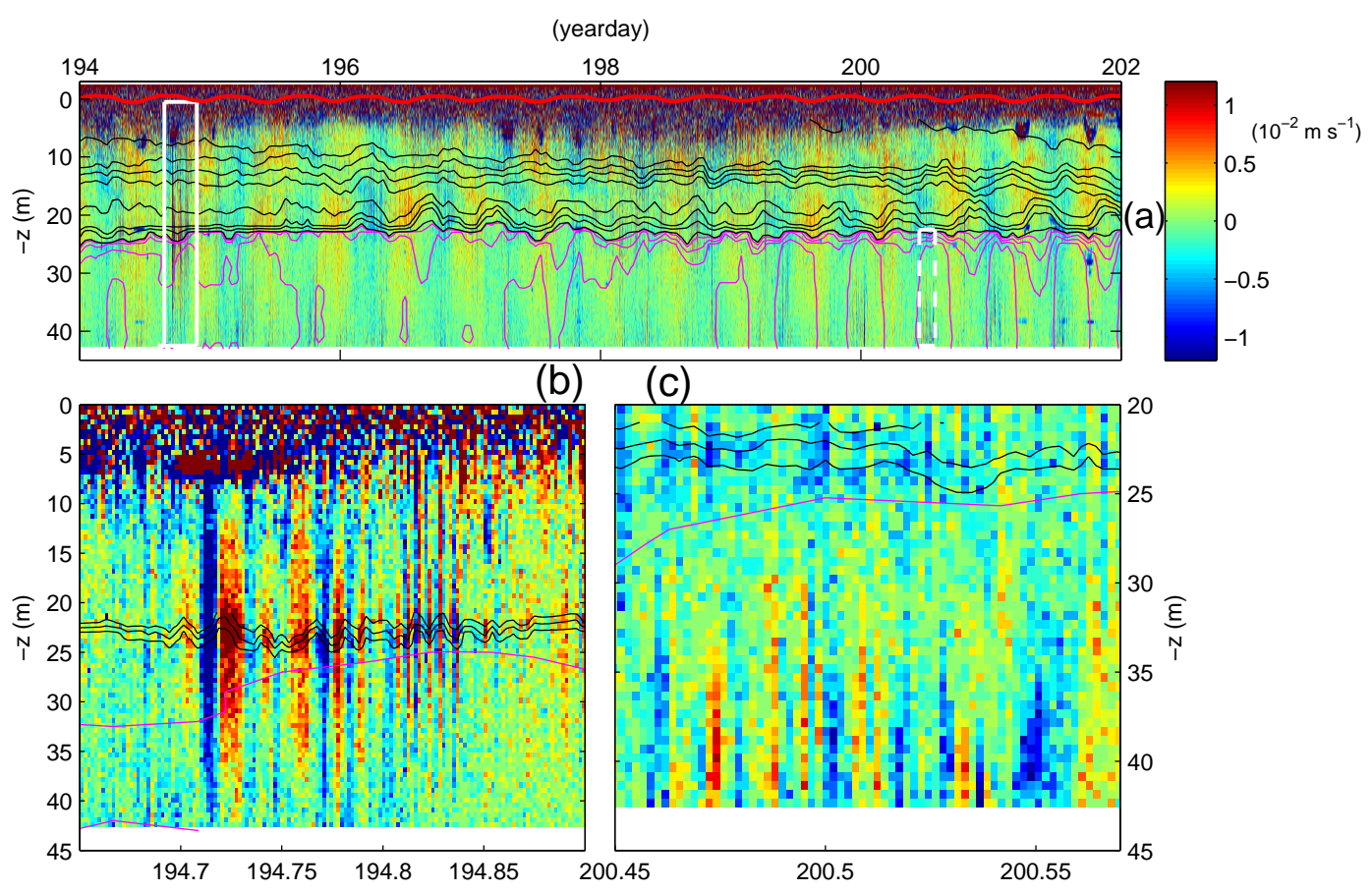

Fig. 3. Summertime INP time series. (a) Vertical current observed using ADCP (colours) with hourly smoothed temperature contours, observed using thermistor string, every $1^{\circ} \mathrm{C}$ between $10-18^{\circ} \mathrm{C}$ (black) and every $0.2^{\circ} \mathrm{C}$ between $9.1-9.9^{\circ} \mathrm{C}$ (purple). The red graph indicates surface elevation variation, observed using a pressure sensor at the bottom. The solid rectangle indicates the period of panel (b), the dashed rectangle that of panel (c). (b) Detail of (a) with high-frequency waves near mid-depth and only one purple contour (9.5 $\left.{ }^{\circ} \mathrm{C}\right)$. (c) Detail of (a) with high-frequency waves near the bottom and only one purple contour $\left(9.3^{\circ} \mathrm{C}\right)$. Note different $\mathrm{z}, \mathrm{t}$ scales compared to (b). In (a-b) the brown band above about $-7 \mathrm{~m}$ represents bad (surface reflection side-band) ADCP-data.

Above a smoothly sloping side of the FSC a bottomlander with ADCP and NIOZ-1 thermistor string was located at $\mathrm{H}=494 \mathrm{~m}$, which is an order of magnitude larger than in the central North Sea. Data are discussed from a two-week deployment sampled at a rate of once per $30 \mathrm{~s}$. Main stratification is around $300-500 \mathrm{~m}$, well below mid-depth and with $\mathrm{T}_{N} \approx 1200-1800 \mathrm{~s}$. This stratification occasionally moves upslope and passes the mooring as a vigorous bore (Hosegood and van Haren, 2004). Outside the main stratification $\mathrm{T}_{N} \approx 3500-7000 \mathrm{~s}$.

\section{Observations of directly and indirectly measured w}

\subsection{North Sea}

In the strongly stratified summertime central North Sea vertical motions are generally weak $\mathrm{O}\left(10^{-2} \mathrm{~m} \mathrm{~s}^{-1}\right)$ and have a dominant semidiurnal tidal periodicity (Fig. 3a). However, these tidal w-motions do not represent free internal waves. This is evident in Fig. 4a-c, where only below the lower pycnocline, in the near-bottom layer, the two terms in Eq. (1) have the same magnitude, but with opposing signs and phase. Here, $w$ is measured by ADCP and T by thermistor string. In all panels $|w \partial \overline{\mathrm{T}} / \partial \mathrm{z}| \gg|\mathrm{e} \partial \overline{\mathrm{T}} / \partial \mathrm{z}|$ with typical variance ratio of $\operatorname{var}(w) / \operatorname{var}(e)=3-10$. The spectra of e are flat, except for a small peak at the inertial frequency "f" in the upper half of the water column where the [vertical] length scales of $\mathrm{f}$ are particularly small and shear is large (van Haren et al., 1999). This small peak still has $\operatorname{var}(\mathrm{e})<0.1 \operatorname{var}(\mathrm{w})$, where the w-peak is at the semidiurnal tidal frequency. As a result, a heat balance can only be achieved via horizontal advection or other terms. In contrast, at the depth of the lower, most stratified, pycnocline, the first two terms do have equal signs, but the magnitude of the vertical advection term is $\mathrm{O}(10)$ times the local temperature time derivative (Fig. 4b). This is also found in the upper pycnocline, where additionally the phase difference between the two terms varies strongly with time (Fig. 4a). As a result, at all three different levels the tidal variations are dominantly governed by horizontal [barotropic tidal] advection of fronts, confirming previous results (Howarth, 1998). There is no phase-locking with the surface tide, compare isotherm variations with the pressure record in (Fig. 3a).

However, small-scale internal "waves" are different. In the overall picture (Fig. 3a), occasional very thin lines can be observed in w, e.g., around mid-depth at days 194.8 (Fig. 3b) and 198.1, and near the bottom, e.g., at days 200.5 (Fig. 3c) and 201.1. Focusing on the time interval with most pronounced w-amplitudes (Fig. 4d), the first two terms of (1) have the same [order of] magnitude, as far as can 

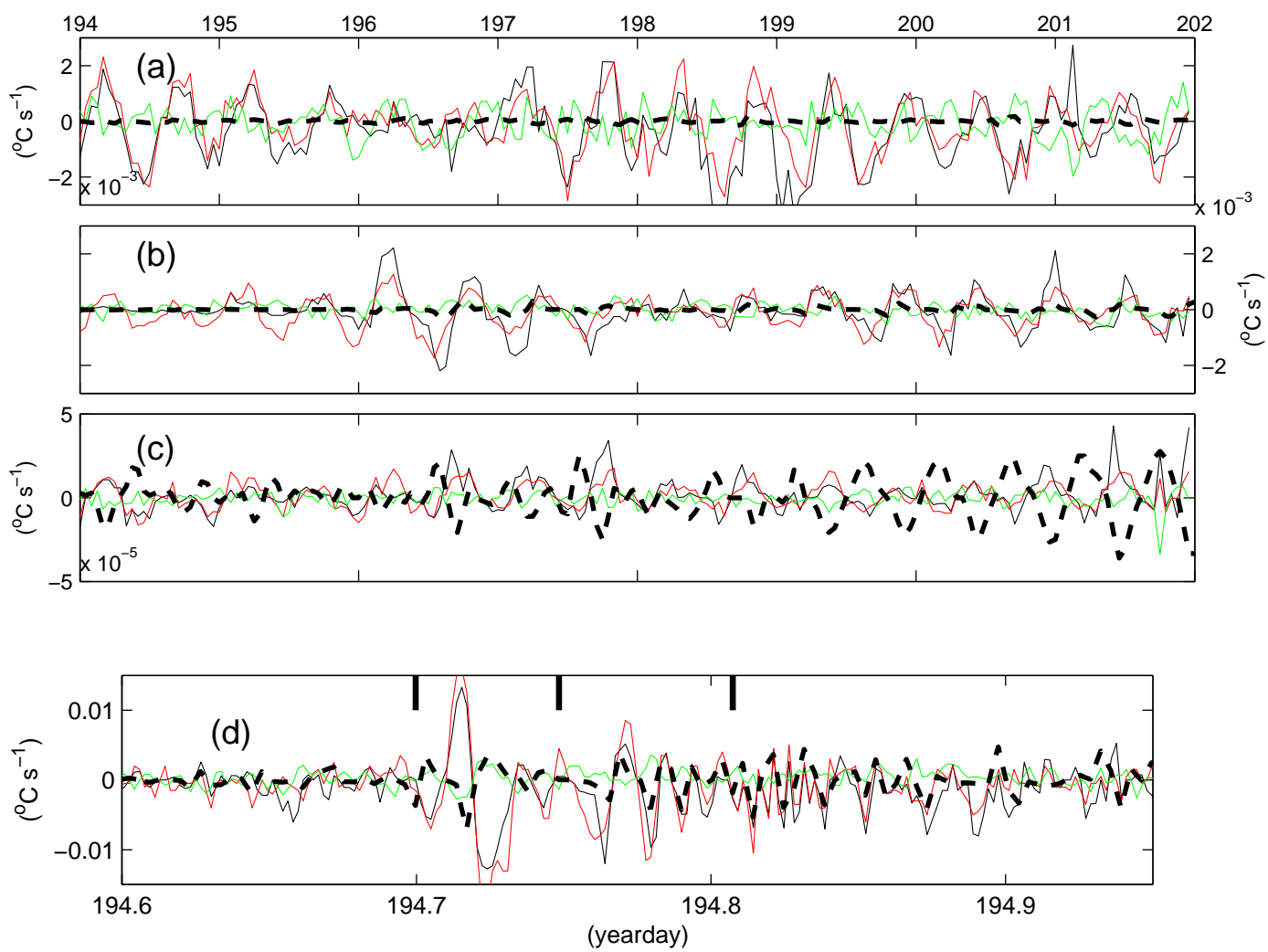

Fig. 4. Comparison of the two terms of Eq. (1) using INP-data: w from ADCP and T from thermistor string. Heavy dashed is $\partial \mathrm{T} / \partial \mathrm{t}$, thin solid lines represent the right-hand side of Eq. (1), in black $-\mathrm{w} \partial \mathrm{T}(\mathrm{t}) / \partial \mathrm{z}$, in red $-\mathrm{w} \partial \overline{\mathrm{T}} / \partial \mathrm{z}$, in green $-\mathrm{e} \partial \overline{\mathrm{T}} / \partial \mathrm{z}$. (a) Total time series, hourly averaged data at $-11.5 \mathrm{~m}$. (b) As (a), but at $-19.5 \mathrm{~m}$. (c) As (a), but at $-31 \mathrm{~m}$. (d) Raw, 5 min sampled T- and averaged w-data at $-22.5 \mathrm{~m}$ for the detailed period of Fig. 3b. Three important transitional periods are indicated (see text). Note the different scales.

be established because the 5-min sampled temperature data do alias the very high frequency motions (e.g., around day 194.82). However, the start of the time interval of substantial high-frequency motions (day 194.70) shows a $\pi$-phase difference for motions that have a period of $1900 \pm 100 \mathrm{~s}$. It is noted that $-\mathrm{e} \partial \overline{\mathrm{T}} / \partial \mathrm{z}$, which is dominated by current inhomogeneities over the beam spread, shows a reasonable correspondence with $\partial \mathrm{T} / \partial \mathrm{t}$. This evidences horizontal advection and diffusion or dominant quadratic and triple derivative terms, as in the $\mathrm{KdV}$-equation describing non-linear solitary waves (e.g., Helfrich and Melville, 1986), prevailing over free [linear] wave propagation. However, from a sudden transition at day 194.75 onwards the shorter scale motions have periods of 1500 decreasing to $420 \mathrm{~s}$ at 194.81 and the first two terms in (1) have the same sign and magnitude, as far as can be inferred from the shortest period waves that are undersampled by the thermistor string. There, $|\mathrm{e}|<<|\mathrm{w}|$ and errors in $\mathrm{w}$ are small. As a result, these latter motions describe more or less linear wave propagation for which Eq. (1) can be used to estimate $w$ from temperature data. Data were too noisy to properly evaluate Eq. (1) for the period in Fig. 3c.

The above examples of Eq. (1) not well describing directly observed $\mathrm{w}$ are confirmed in the spectral domain (Fig. 5). In contrast with open ocean data (Fig. 1), the over- all spectra of temperature-inferred $\mathrm{w}$ and ADCP-w poorly match for the North Sea data, especially near the semidiurnal frequency (Fig. 5a). Despite the small amplitudes, ADCP's w-estimate is significantly exceeding noise levels. Only for the small periods of Fig. 3b some comparison is found between ADCP-w and temperature-inferred w, albeit mostly for small-scale $\mathrm{N}$ in the lower pycnocline, $\mathrm{T}_{N}=420 \mathrm{~s}$ (Fig. 5b). It is noted that the best spectral amplitude comparison for large-scale $\mathrm{N}$ is found between pycnocline temperature variations and near-bottom ADCP w-estimate. ADCP's $\mathrm{w}$ in the pycnocline shows larger amplitudes. This suggests that the bottom boundary layer drives these linear pycnocline motions, but that the enforcement of the pycnocline w(N) peak is highly non-linear and dominated by the first few periods (see Fig. 4d). Also in the entire record mean spectrum (Fig. 5a) lower-pycnocline temperature-inferred w correspond best with the level of near-bottom ADCP-w, but only for $\sigma>5 \mathrm{cpd} \approx 4 \mathrm{f}_{h}, \mathrm{f}_{h}=2 \Omega \cos \varphi$ the horizontal component of the Earth rotational vector $\boldsymbol{\Omega}$ at latitude $\varphi$. This suggests linear waves between $\mathrm{N}$ and this cut-off and non-linear motions for lower frequencies including tidal, inertial and sub-inertial frequencies. 
Table 2. Thermistor string mooring details. AA=Aanderaa, NIOZ=Netherlands Institue for Sea Research design (van Haren et al., 2001). The modified AA-thermistor string has standard sensors that are connected to aluminium plates cut in the rubber tube that holds the entire string and strength member. This decreases the response time.

\begin{tabular}{lllllll}
\hline INP summer & \# sensors & depths & samp.int & $\tau$-resp & resolution & accuracy \\
\hline AAstandard “upp" & 10 & $3-21 \mathrm{~m}$ & $600 \mathrm{~s}$ & $60 \mathrm{~s}$ & $0.02^{\circ} \mathrm{C}$ & $0.1^{\circ} \mathrm{C}$ \\
AAmodified "mid" & 11 & $21-31 \mathrm{~m}$ & $300 \mathrm{~s}$ & $10 \mathrm{~s}$ & $0.02^{\circ} \mathrm{C}$ & $0.1^{\circ} \mathrm{C}$ \\
AAstandard "low" & 11 & $23-43 \mathrm{~m}$ & $1800 \mathrm{~s}$ & $60 \mathrm{~s}$ & $0.02^{\circ} \mathrm{C}$ & $0.1^{\circ} \mathrm{C}$ \\
\hline PROCS spring & & & & & \\
\hline NIOZ-1 & 32 & $461-492 \mathrm{~m}$ & $30 \mathrm{~s}$ & $0.25 \mathrm{~s}$ & $50 \mu \mathrm{K}$ & $<0.5 \mathrm{mK}$ \\
\hline
\end{tabular}
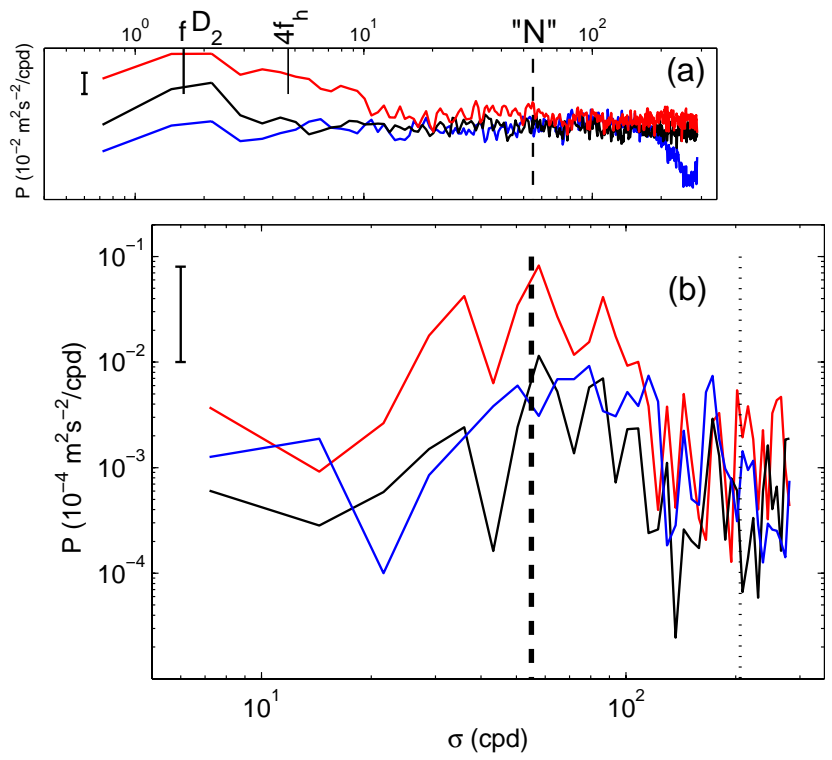

Fig. 5. W-spectra from summertime INP ADCP-data at $-22.5 \mathrm{~m}$ (red) and $-39.5 \mathrm{~m}$ (black), in comparison with $\mathrm{w}$ at $-22.5 \mathrm{~m}$ inferred from temperature data using Eq. (1) (blue). (a) For entire 8-days period. (b) For period of Fig. 3b between days 194.70 and 194.85. The dashed line indicates the buoyancy frequency corresponding to a period of $1600 \mathrm{~s}$ ( bottom boundary layer) and the dotted line indicates a period of $420 \mathrm{~s}$ (lower pycnocline).

Estimates of turbulent diffusion indicate values of about $\mathrm{K}=6 \cdot 10^{-4} \mathrm{~m}^{2} \mathrm{~s}^{-1}$ across the pycnocline during the passage of the high-frequency [non-]linear wave, which gives values of $3-4 \cdot 10^{-5} \mathrm{~m}^{2} \mathrm{~s}^{-1}$ integrated over a tidal period (van Haren et al., 1999). This overall value is sufficient for nutrient transport generating the summer phytoplankton bloom, and these occasional near- $\mathrm{N}$ waves also govern the slow heating of the near-bottom layer during spring and autumn. Comparable $\mathrm{K}$-values are observed on the Malin Shelf and attributed to non-linear high-frequency waves (Inall et al., 2000).

For all of the above evaluations of Eq. (1) $<10 \%$ improvement is obtained using instead of $\partial \mathrm{T}(\mathrm{t}) / \partial \mathrm{z}$ its time mean (Fig. 4). However, the influence of the time dependence is larger in a region where strongly turbulent non-linear "waves" or bores prevail, like above a FSC-slope.

\subsection{Faeroe-Shetland Channel}

Similar vertically striped, generally mode-1, w-motions are observed albeit in irregularly occurring groups in the FSC and associated with non-linear wave trains moving up the slope (Hosegood and van Haren, 2004). In the FSC, vertical currents associated with high-frequency motions are larger (by a factor of 3-4) than in the central North Sea, commensurate with the equally weaker stratification that supports them. As a result, one could "conclude" that $|\mathrm{w}| \sim \mathrm{N}^{-1}$, rather than $\sim \mathrm{N}^{-1 / 2}$, which is more common for horizontal currents.

Despite the very accurate thermistor string (Table 2 for its characteristics) the vigorous motions cause substantial turbulent overturning, i.e. by definition not linear waves. This explains the difficulty in evaluating Eq. (1) using these data and spikes are regularly large, especially in temperature-inferred w (Fig. 6d).

However, the frontal upward $\mathrm{w}$-jet, exceeding $0.1 \mathrm{~m} \mathrm{~s}^{-1}$, is detected by both inferred and direct measurements, which is surprising when compared with the first "wave" period of small-scale North Sea motions (Fig. 4d). The small phase lag of 30-60 s between the differently observed jet in the FSC (Fig. 6d) is attributable to the ADCP's beam spread in combination with thermistor string motions due to current drag. Only then, non-negligible e is found (Fig. 6c). Regular large-scale, indeed $\sim 1500 \mathrm{~s} \sim \mathrm{T}_{N}$ period, and occasionally very high frequency motions, are adequately described by Eq. (1). The best comparison with ADCP's w is obtained using $\partial \mathrm{T}(\mathrm{t}) / \partial \mathrm{z}$ rather than its time mean, which implies that a non-linear term is needed to dampen some of the highfrequency spiking, but in the vertical direction only. Unfortunately, the data do not allow the evaluation of horizontal non-linear terms, responsible for the (turbulent) spikes during other periods. The local turbulent diffusivity is large, $\mathrm{K} \sim \mathrm{O}\left(10^{-1} \mathrm{~m}^{2} \mathrm{~s}^{-1}\right)$ (Hosegood and van Haren, 2004), but the passage is so rapid that the value integrated over a tidal period is similar to the one above that was estimated for the North Sea. 


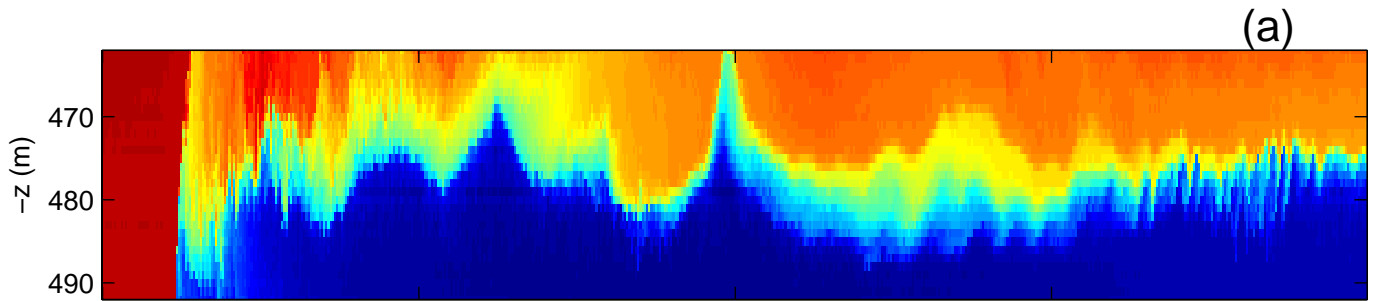

(b)

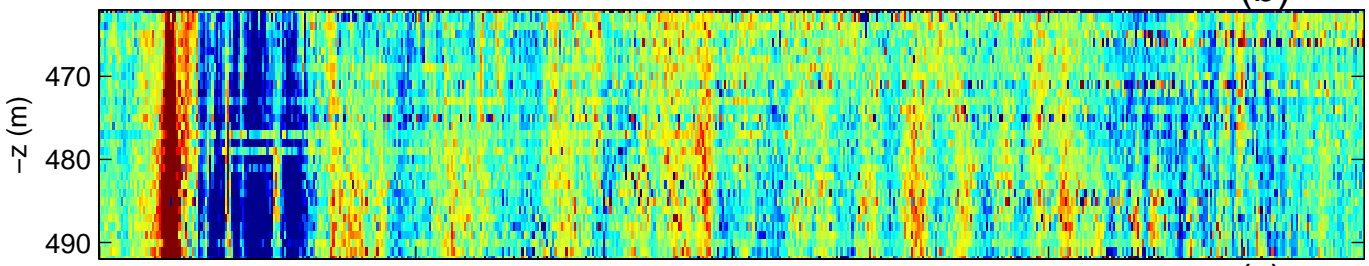

(c)
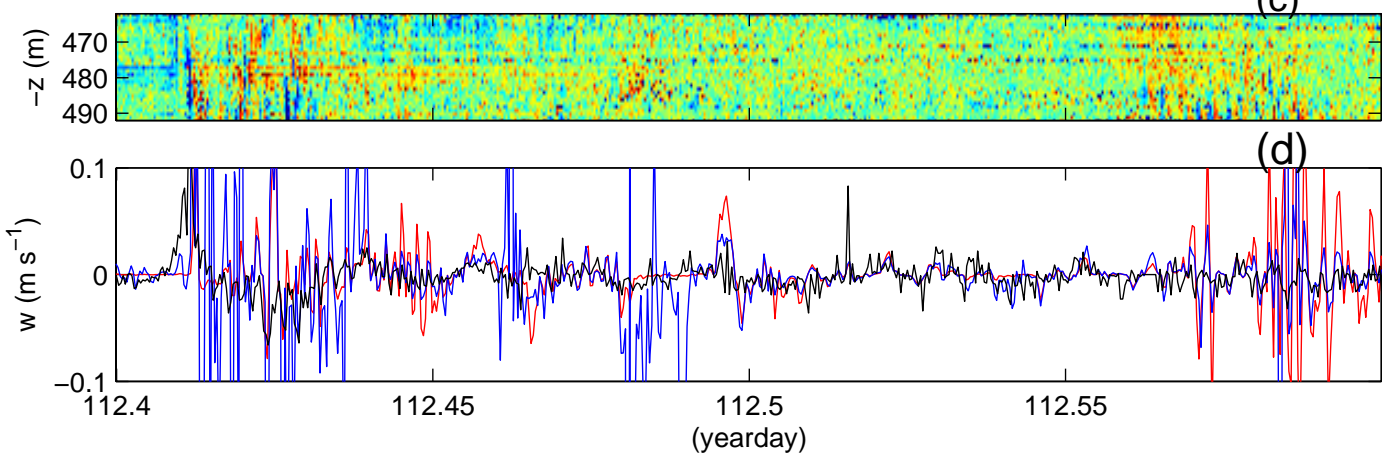

Fig. 6. W-test for frontal solibore in 5-h detail in FSC-data. (a) High-resolution temperature measured using NIOZ-1. Values between [2, $8]^{\circ} \mathrm{C}$ (blue-red). (b) Corresponding ADCP's w-data. Values truncated between $[-0.03,003] \mathrm{m} \mathrm{s}^{-1}$ (blue-red). (c) Like (b) but for e-data. (d) $\mathrm{W}$ at $477 \mathrm{~m}$ from ADCP (black) and inferred from temperature data using Eq. (1) and unsmoothed local vertical temperature gradient (blue), and time mean temperature gradient (red).

\section{Discussion}

It has been shown that direct w-observations describe realistic ocean phenomena that have horizontal length scales larger than an ADCP's beam spread, being $10 \mathrm{~m}$ here. The present data do not [directly] represent free convection, but rather [non-]linear internal waves or frontal advection (cf., Fig. 4). A strong association between the motions' periodicity and depth of maximum amplitude with stratification favours an explanation in terms of internal waves, e.g. (Fig. 3b). This has been confirmed using Eq. (1), but it is found that this standard method to compute $\mathrm{w}$ from T-data does not work in a tidal advection area like the North Sea or in an area where non-linear motions prevail over linear [high-frequency] waves.

The observation that $\partial \mathrm{T}(\mathrm{t}) / \partial \mathrm{z}$ is better used than its time mean in turbulent near-bottom areas and that non-linear near$\mathrm{N}$ motions dominate the internal "wave" spectrum near its upper bound in the ocean interior may also explain the discrepancy in w-spectra from the Bay of Biscay (Fig. 1). Presumably, weakly non-linear waves likewise dominate the ocean continuum as well, possibly as interfacial waves like in the North Sea, because the ADCP's w-data exceed noise level, as determined using e, and temperature-inferred $\mathrm{w}$ at frequencies between tidal harmonics, e.g. between semidiurnal and fourth-diurnal bands in Fig. 1.

The lack of dominant linear high-frequency waves may explain the quarter-wave period discrepancy between $\mathrm{T}$ and $\mathrm{w}$ observations found by Hallock and Field (2005). It certainly explains East China Sea observations by Lee et al. (2006), who found 3 large "waves" of depression before a group of about 10 higher frequency waves, just like in Fig. 3b. As for the North Sea observations presented here, the sudden change in phase difference between time derivative and vertical advection terms in Eq. (1) after the first two wave periods bears some resemblance with laboratory experiments on the generation of mode- 2 internal waves following an intrusion in a linearly stratified fluid (Amen and Maxworthy, 1980). Although no w-observations were presented by these authors, the gravitational collapse of a mixed region generated two mode- 2 solitary waves followed by a train of constant amplitude mode- 1 waves of approximately doubled frequency. When sufficiently strong, mode- 2 waves can appear as closed contour "waves", with importance for 
transporting material (Davis and Acrivos, 1967). Here, they are only observed in limited form, at the top of the bottomboundary layer (Fig. 3), and, peculiarly, [two] mode-1 waves precede mode- 2 waves. More modeling is required to establish the generation of such waves, although it has been shown that mode- 2 waves can [occasionally] follow a mode- 1 wave breaking on a sloping shelf (Helfrich, 1992).

More modeling is also required to establish whether a nonzero limit value exists to diapycnal diffusivity across strong stratification, as suggested by the tidal mean value found in different regions presented here and which are apparently induced by high-frequency non-linear motions.

Similarly, more modeling is required to establish the large discrepancy between directly measured and temperatureinferred w at sub-inertial frequencies. Certainly, the assumption underlying Eq. (1) does not include gyroscopic waves, which are prevalent in homogeneous layers in the frequency range $[0,2 \Omega]$. These waves show relatively large $\mathrm{w}$ that can be directly measured and which extend spectrally to about $\sigma=4 \mathrm{f}_{h}$ before dropping into noise in a very weakly stratified, near-homogeneous area like the deep Mediterranean Sea (van Haren and Millot, 2005). They are not measured by temperature sensors in homogeneous layers. In a stratified ocean however, the internal wave band [continuum] drops off for $\sigma<4 \mathrm{f}_{h}$, but faster for temperature-inferred w than ADCP's w (Fig. 1a). Apparently also small-scale advection or eddies are not incorporated by Eq. (1), which gives the impression of a strict internal wave band consisting only of tidal harmonic motions dropping off for $\sigma<\mathrm{f}$, but which is unrealistic in terms of oceanic low and high-mode w.

Acknowledgements. The assistance of the crew of R/V Pelagia is highly appreciated. I thank Theo Hillebrand for mooring preparation. Integrated North Sea Program (INP) and Processes above Continental Slopes (PROCS) were funded in part by the Netherlands Organization for the advancement of Scientific Research (NWO).

Edited by: W. Dewar

\section{References}

Amen, R. and Maxworthy, T.: The gravitational collapse of a mixed region into a linearly stratified fluid, J. Fluid Mech., 96, 65-80, 1980.

Davis, R. E. and Acrivos, A.: Solitary internal waves in deep water, J. Fluid Mech., 29, 593-607, 1967.

Hallock, Z. R. and Field, R. L.: Internal-wave energy fluxes on the New Jersey Shelf, J. Phys. Oceanogr., 35, 3-12, 2005.

Helfrich, K. R.: Internal solitary wave breaking and run-up on a uniform slope, J. Fluid Mech., 243, 133-154, 1992.

Helfrich, K. R. and Melville, W. K: On long nonlinear internal waves over slope-shelf topography, J. Fluid Mech., 167, 285308, 1986.

Hosegood, P. and van Haren, H.: Near-bed solibores over the continental slope in the Faeroe-Shetland Channel, Deep-Sea Res. II, 51, 2943-2971, 2004.

Howarth, M. J.: The effect of stratification on tidal current profiles, Cont. Shelf Res., 18, 1235-1254, 1998.

Inall, M. E., Rippeth, T. P., and Sherwin, T. J.: Impact of nonlinear waves on the dissipation of internal tidal energy at a shelf break, J. Geophys. Res., 105, 8687-8705, 2000.

Krauss, W.: Methoden und Ergebnisse der Theoretischen Ozeanographie, II Interne Wellen, Gebrueder Borntraeger, Berlin, 248 pp., 1966.

Lee, J. H., Lozovatsky, I., Jang, S.-T., Jang, C. J., Hong, C. S., and Fernando, H. J. S.: Episodes of nonlinear internal waves in the northern East China Sea, Geophys. Res. Lett., 33, L18601, doi:10.1029/2006GL027136, 2006.

Pinkel, R.: Observations of the near-surface internal wavefield, J. Phys. Oceanogr., 11, 1248-1257, 1981.

van Aken, H. M., van Haren, H., and Maas, L. R. M.: The highresolution vertical structure of internal tides and near-inertial waves, measured with an ADCP over the continental slope in the Bay of Biscay, Deep-Sea Res. I, 54, 533-556, 2007.

van Haren, H. and Millot, C.: Gyroscopic waves in the Mediterranean Sea, Geophys. Res. Lett. 32, L24614, doi:10.1029/2005GL023915, 2005.

van Haren, H., Maas, L., Zimmerman, J. T. F., Ridderinkhof, H., and Malschaert, H.: Strong inertial currents and marginal internal wave stability in the central North Sea, Geophys. Res. Lett., 26, 2993-2996, 1999.

van Haren, H., Groenewegen, R., Laan, M., and Koster, B.: A fast and accurate thermistor string, J. Atmos. Oceanic Technol., 18, 256-265, 2001. 